\title{
Personal professional identity formation through interprofessional learning and early patient encounter during preclinical years
}

\author{
Leo Brandt
}

Faculty of Medicine and Health Sciences, Linköping University, Linköping, Sweden

Medical education usually consists of teaching extensive medical knowledge and understanding the clinical aspect of the health care profession. Thomas J. Lawley discussed the old school of thought on medical education with a focus on the "Hopkins" model of teaching and the need for reform in some ways to fit the current healthcare system and the future [1].

Learning about human physiology and pathology is vital and indispensable to a medical student. However, in my opinion, there are other qualities that are often neglected in traditional medical education, which would help improve patient-focused care-such as soft skills. I feel that such qualities are often an overlooked part of medical education. There are different approaches to learning soft skills, but there are options in medical education where you can combine the clinical aspect of healthcare and learning soft skills, at the same time. Fortunately, I have had wonderful opportunities to learn soft skills while learning clinical and basic medicine in my medical school. I would like to share my learning experience of soft skills and how it has affected my professional identity formation.

In Sweden, we have seven medical universities, and all of them are public universities without tuition fees. Students from upper secondary school apply directly to one of the medicine programs. The curriculum of these medical schools consists of 5.5 years of studies. There is no grading; only a pass or a fail is given based on students' academic achievement. After 5.5 years of basic medical studies, graduates must undertake a foundation program for at least 1.5 years to be eligible for a medical license.

Before I chose my medical school, I reviewed the curriculum structure and type of students' learning in each school. I concluded that I did not want to study in the traditional way, with lectures for days on end. Linköping University is one of the most innovative among the seven medical universities in Sweden, where the curriculum is based on problem-based learning (PBL), integrated interprofessional education (IPE), and
Received: July 27, 2017 • Revised: July 31, 2017 • Accepted: July 31, 2017 Corresponding Author: Leo Brandt (https://orcid.org/0000-0002-6270-5335) Linköping University, Sandbäcksgatan 7, Linköping, 582 25, Sweden Tel: +46.706.16.56.88 email: Leo.j.brandt@gmail.com
Korean J Med Educ 2017 Sep; 29(3): 203-205.

https://doi.org/10.3946/kjme.2017.67

eISSN: 2005-7288

(C) The Korean Society of Medical Education. All rights reserved. This is an open-access article distributed under the terms of the Creative Commons Attribution Non-Commercial License (http:// creativecommons.org/licenses/by-nc/3.0/), which permits unrestricted non-commercial use, distribution, and reproduction in any medium, provided the original work is properly cited. 
early clinical exposure (ECE). At Linköping University, the first 2.5 years involve PBL-based theoretical studies and the last 2.5 years involve clinical clerkship. The 6th semester between theoretical studies and clerkship is entirely allocated for students to complete their thesis project.

The importance of the IPE concept has increased, and the World Health Organization is amongst its supporters [2]. In the IPE program, a student practices on interdisciplinary work in a healthcare context and learns about essential soft skills, such as communication and teamwork - getting an understanding of each healthcare profession and how to best put the skills together to form an efficient team. Healthcare should be patientfocused, and when we see improved teamwork in a healthcare team, it also enhances patient care $[3,4]$. In my school, students are engaged in IPE in the first and fifth semester.

As a new medical student, I was at first skeptical towards being in a group with different disciplines because I wanted to acquire knowledge of my profession and not necessarily how to work together with others from different professions. Later, I was very grateful for this curriculum. I felt that I had learned a lot through the opportunity to work together with the other healthcare professionals. All the students contributed different perspectives more so than in a group, with students from the same profession. Most of the time, we approached cases from different angles. I as a medical student, for example, have never considered the quality of life for a patient from the onset because I was too focused on the medical aspect.

The second part that I would like to share my experience on is the early and frequent patient contact. In my university, we have a program that pertains to patient contact and conversation knowledge: this program requires students to meet real patients from the first semester. Every other week, students from the same PBL group will visit a community healthcare center and spend a whole day meeting patients. The group meets with several patients, and the student-patient encounter is video recorded. At the end of the day, the students will review the videos and discuss their conversations with the patients together with a tutor who is a doctor in the healthcare center. During the patient discussions, we focus on learning the ICE approach-ideas, concerns, and expectations of the patient.

The biggest benefit of early patient exposure is that the focus is on communication and not on medical knowledge. After mastering the communication aspect, it was easier to try and apply medical knowledge. My concern at first for the early patient contact was that I had too little clinical knowledge. In addition, I assumed that I already knew how to communicate with patients efficiently. However, I was surprised with to the difficulty of conducting a productive and efficient conversation with a patient. Patients are all so different; some patients arrived at a clinic with a goal in mind, whereas some liked to talk about everything, and some were very quiet and did not speak at all. The most difficult thing for me was to be able to be quiet and let the patient speak. I found myself interrupting more often than I thought when I was in such encounter. Later, I identified the underlying reason for this-I feared pauses in conversations. I also noticed how my body language was interfering in the conversation. After every conversation, I watched myself through the video recordings, and I could find new things to improve on.

By experiencing ECE and IPE in my education, I have become more prepared for my upcoming clerkship. By practicing working in interdisciplinary teams and early patient contact facilitates students' smooth transition from theoretical studies to clerkship period by making it less abrupt. Integrating ECE in medical education is a 
vital part of letting the students become more selfconfident when they meet patients during their clinical clerkship.

To summarize, I think real patient contact and having an interdisciplinary healthcare environment before the commencement of clerkship is helpful in developing a professional identity formation of medical students. Based on my personal experience, early patient exposure and IPE learning can help students obtain important soft skills such as decision making, leadership, creativity and problem-solving skills, all which are useful abilities in clinical practice.

\section{ORCID:}

Leo Brandt: https://orcid.org/0000-0002-6270-5335

Acknowledgements: This essay was written while my studying in Korea University College of Medicine, Seoul as an exchange research program (SCORE) sponsed by IFMSA (International Federation of Medical Students Assocation).
Funding: None.

Conflicts of interest: None.

\section{References}

1. Lawley TJ, Saxton JF, Johns MM. Medical education: time for reform. Trans Am Clin Climatol Assoc. 2005; 116:311-320.

2. Learning together to work together for health: report of a WHO study group on multiprofessional education of health personnel: the team approach. World Health Organ Tech Rep Ser. 1988;769:1-72.

3. Freeth D, Hammick M, Reeves S, Koppel I, Barr H. Effective interprofessional education: development, delivery, and evaluation. New York, USA: John Wiley \& Sons; 2008.

4. Barr H, Koppel I, Reeves S, Hammick M, Freeth D. Effective interprofessional education: argument, assumption \& evidence. Oxford, UK: Blackwell Publishing Ltd.; 2005. 